\title{
Teaching Strategies of Innovation and Entrepreneurship for Animation Major in Colleges and Universities
}

\author{
Hong Shi ${ }^{1, *}$ \\ ${ }^{1}$ College of Arts \& Design, JMU, Xiamen, 361021, China \\ *Corresponding author. Email: rainjay@jmu.edu.cn
}

\begin{abstract}
This work aims to improve the ability and solve the problem of cultivating innovation and entrepreneurship ability of students majoring in animation. Starting from creating "animation IP", the work closely adheres to the cooperative learning mode of "learning by competition". Also, this work attempts to help the university enterprise cooperation and collaborative education strategy, and finally obtains a complete set of teaching strategies to improve the ability of innovation and entrepreneurship. Among them, "the creation of 'animation IP' based on regional culture" and "cooperative learning based on learning by competition" are the main novelties of this work.
\end{abstract}

Keywords: Animation major, Innovation and entrepreneurship, Animation IP, Cooperative learning,

University enterprise cooperation

\section{INTRODUCTION}

\subsection{Research Background}

With the advent of the digital Internet era, the boundary of the animation industry has been continuously expanded. Animation has gradually extended from the art field to multi-disciplinary fields. At the same time, it is closely integrated with the Internet economy, artificial intelligence, virtual reality and quadratic element culture, thus becoming an important part of the current cultural economy. The rapid development of digital creative industry has also triggered a competitive situation with "content is king" as the core.

The transformation of the industry has induced new requirements for the cultivation of innovation and entrepreneurial ability of animation creative talents. Only by promoting the closer combination of innovation and entrepreneurship education and professional education, allowing students to consolidate professional knowledge in innovation and entrepreneurship, and improving innovation and entrepreneurship ability in professional education, a large number of high-quality talents who can innovate and start businesses for economic and social development shall be cultivated [1]

\subsection{Research Status and Shortcomings}

Since the beginning of this century, animation higher education has experienced a short period of rapid development. In terms of talent training, it has played an important role in improving the discipline structure, expanding teaching resources, reserving professional teachers and providing creative talents. At the same time, it has also caused some universities to copy each other in terms of professional orientation, education mode, curriculum system and teaching methods of animation talent training. It leads to the waste of teaching resources and the lack of innovative development, which reflects the lack of scientific grasp of the long-term development of animation education to a certain extent [2].

Through the form of questionnaire, this work investigates 7 professional teachers and 120 students majoring in animation in Jimei University. The results show that $100 \%$ of students and teachers believe that the quality of animation works is directly proportional to the creator's innovation and creativity; $74 \%$ of students believe that the entrepreneurial environment can stimulate their creative enthusiasm and initiative, and $86 \%$ of teachers believe that cultivating students' entrepreneurial spirit can improve their team consciousness and sense of responsibility, as shown in Fig. 1.

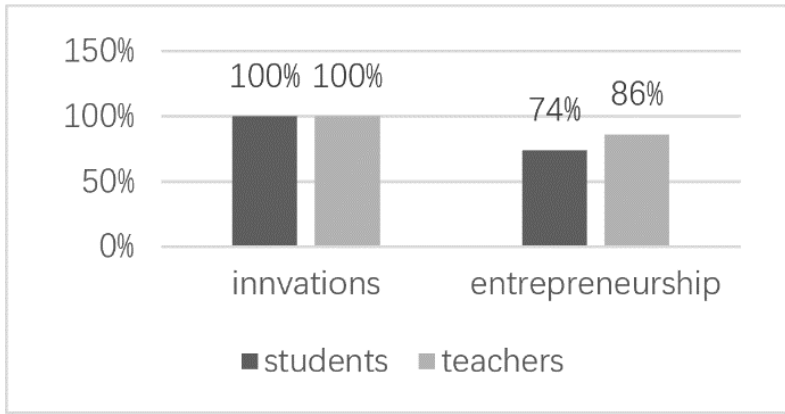

Figure 1. Necessity survey of innovation and entrepreneurship ability

It can be seen that it is the common expectation of animation teachers and students to integrate the cultivation of 
innovation and entrepreneurial ability into the traditional curriculum system.

\subsection{The Scheme and Advantages of This Research}

Based on the traditional teaching method of animation major in Chinese colleges and universities, the research puts forward the teaching method guided by "innovation and entrepreneurship". The research changes the traditional teaching method, which is decentralized, unsystematic and disconnected from the industry. It combines the cooperative learning of creating "animation IP" and "learning by competition", university enterprise cooperation and collaborative education strategy to improve students' ability of "innovation and entrepreneurship". The purpose is to meet the new requirements of the development of digital creative industry for the cultivation of talents in colleges and universities.

\section{CREATING THE TEACHING STRATEGY OF "ANIMATION IP" WITH REGIONAL CULTURE}

IP is the English abbreviation of Intellectual Property, implying something imagined by the human brain and endowed with the right of execution and protection. "Animation IP" is the intellectual property of animation works. It is based on animation visual image symbols. It covers many types, including film and television animation characters such as Mickey Mouse, game characters such as Super Mario, cultural and tourism animation IP such as Kumamon, commercial animation characters such as Hello Kitty, etc.

Accelerating the incubation of "animation IP" is not only an effective way to promote the development of China's animation industry, but also an emerging driving force to promote the in-depth integration of China's animation industry and other industries to create "super IP". In the teaching process of animation specialty, if we can always implement the teaching concept of "animation IP", it is an effective way to cultivate students' innovative and entrepreneurial thinking and improve their innovative and entrepreneurial ability. It can be started from the following aspects.

\subsection{Arrange Teaching Contents in Combination with Regional Culture}

The most eye-catching thing in Hollywood animation films is the innovative thinking expression of regional cultural resources. It enables the audience to quickly identify the figure of their own culture from their animation works, so as to stimulate the corresponding cultural identity.
To guide students to effectively find a breakthrough in IP creation, it can start from the local culture with obvious regional characteristics. While stimulating students' innovative thinking, it can also be influenced by humanistic quality education. Regional culture contains the living habits, survival wisdom, aesthetic tendency and the origin of value system of the people in the region [3], from which fresh and rich humanistic education and creative materials can be extracted.

In the teaching of basic animation creation, such as animation modeling design, animation scene design, twodimensional animation creation and other courses requiring students to complete original works, it can take understanding local culture as the leading part of the course. In the early stage of curriculum teaching, local cultural elements should be introduced in a targeted way. Through the guidance of teachers, students can understand the folk customs and customs hidden in regional culture; then let students feel the artistic value and aesthetic taste of local culture by means of on-the-spot investigation; further learn about the development history and famous figures of the region by visiting local museums and memorial halls.

\subsection{Reconstructive Creative Training of Regional Culture}

In teaching, it should integrate the refining and sublimation training of cultural connotation. Gelei Chen, the founder of Zhang Xiaohe, the famous animation IP, pointed out in his book "Principles of Super IP Incubation": various cultural matrices are different cultural consensus systems precipitated from human spiritual life for a long time. They are composed of beliefs, legends, characters, symbols and rituals. They are powerful public IP (non privately-owned), the energy source and base of the new IP [4].

To become IP, animation works should not only form a unique sense of symbol identification in image, but also have a sense of hierarchy in spiritual and cultural connotation, so that they can obtain industrial value empowerment. Historical figures, art, folk customs and other elements in regional culture have natural IP attributes (for Xiamen, there are historical celebrities such as Chenggong Zheng and Jiageng Chen), which itself is a regional cultural symbol to be developed.

In the creative practice, the local prototype is used for the design and production of character animation modeling, so as to improve students' innovation thinking and creative ability. Connecting with the local Cultural and Tourism Department, and developing animation cultural and creative tourism products on its basis, so that students can obtain entrepreneurial experience.

In this innovative way, the regional culture is broken up rationally and reconstructed for "breaking dimension". It uses the form of deconstruction and reorganization, on the basis of maintaining the essence of cultural connotation, encourage students to boldly carry out various attempts and training, integrate their own design style and strengths, and design original works derived from local culture and higher 
than local culture. The animation major of Jimei University took the patriotic overseas Chinese "Jiageng Chen" as the IP prototype for secondary development and creation in the animation character modeling class and two-dimensional animation creation class.

\subsection{Create "Animation IP" According to the Teaching Process}

\subsubsection{Integrate the creation of "animation IP" into daily teaching}

Animation production is a process operation, and all links are closely related and indispensable. The professional teaching plan is reasonably planned according to the animation production process to ensure the coherence and sustainability of teaching and creation. In the teaching process, it guides students to create "animation IP" for the creative purpose combined with the daily course teaching of the University.

From the first year of university, it can take "animation IP" as the key link of professional basic courses, such as Introduction to Animation, World Animation History and other theoretical courses. Focusing on its diversified interactive teaching links, analyzing the economic value and social effects of all kinds of animation IP, the growth factors of world super animation IP and so on, it can promote students' positive thinking and discussion, so as to obtain the essential cognition of "animation IP". In the creative courses integrating theory with practice, such as Animation Modeling Design, Cartoon Creation, Two-dimensional Animation Creation, it allows students to build "animation IP" around their original works, give the setting of character outlook on life, values and world outlook, and create a series of vivid characters.

\subsubsection{Use the graduation design to create a complete animation IP}

The graduation design cycle of animation major is relatively long. At present, in the curriculum teaching plans of colleges and universities at home and abroad, the time usually accounts for a whole semester. The whole graduation project is the core teaching link that can better produce original IP.

The graduation design link can give full play to students' innovative thinking and creative ability. Combined with the previous knowledge, from scratch, it goes through the early planning stage, the middle production stage, and the later synthesis and output work. According to the industry production standards, it creates animated short films with certain artistic level and cultural value.

In addition to creating short films, the design scope can be increased to the design of corresponding animation derivatives on the basis of original short films. At the graduation design exhibition stage, the information such as the purchase channel of animation derivatives and the sales price of corresponding commodities can be marked, so as to realize the transformation from IP to economic value through the purchase behavior of visitors. In this way, it can not only enrich the content of professional exhibitions, but also improve the teaching effect of innovation and entrepreneurship.

For example, Jimei University adopted this method in the 2021 animation graduation design exhibition. For the original animation IP derivatives developed for short films, many of them were sold out during the sales period on the last day of the exhibition, and some even had to add product orders.

\section{COOPERATIVE LEARNING STRATEGY OF "LEARNING BY COMPETITION"}

\subsection{The Function of Subject Competition}

Professional subject competition is an effective means to promote the cultivation of students' innovative and creative ability. In recent years, the Higher Education Department of the National Education Department has launched several creative design competitions for national colleges and universities students through the provincial education administrative departments every year, such as the National College Student Advertising Art Competition, Chinese Good Creativity Competition, the National Colleges and Universities Digital Art Design Competition, etc. In addition, provincial and municipal education departments will also regularly hold some competitions with local characteristics. These professional events cover a wide range, involve many students, and have strong cross attributes of art and science and technology. They are a deep-seated comprehensive practical teaching platform to show themselves, observe learning, improve ability and test results.

\subsection{The Importance of Cooperative Learning}

The technique and process of animation production determine that most animation films need to be completed by team cooperation. Although the traditional teaching mode can strengthen students' subjective initiative and competitive consciousness in creation to a certain extent, it virtually weakens students' consciousness of innovation, entrepreneurship and team. After animation specialty students enter the industry, the factor that determines their success is not only professional skills, but the comprehensive quality of various abilities.

Cooperative learning is a creative and effective teaching theory and strategy that rose in the United States in the early 1970s and made substantial progress from the mid-1970s to the mid-1980s. [5] In a mutually cooperative learning environment, students find out problems, exchange ideas, 
design solutions, complete tasks, reflect on their views and experience, and jointly acquire knowledge and improve their ability in the process of cooperation. In the process of creative practice teaching, it guides students to establish a good creative team and jointly create entries in the mode of cooperative learning. It will break the teacher-centered heuristic teaching, which is mainly taught by teachers and supplemented by students' independent design, and change into a student-centered cooperative learning model.

\subsection{Determine the Method of Grouping}

A good team needs a long-term running in among its members. Before starting to create, it should first determine the team members. The selection of team members should be based on the principle of individual heterogeneity and complementarity, not free for students to match. It is embodied in the complementarity of professional skills and team personality. Professional teachers have a certain understanding of students' professional advantages, and it is convenient to arrange groups according to complementary skills. It can avoid the homogenization of team members' skills, resulting in the two-level differentiation between excellent students in different teams. However, for individual team personality, it needs to go through a professional "team personality test" to get a general understanding. At this time, it can quote the test questionnaire commonly used in the industry to know the personality tendency of each student's leadership, team power, creativity and execution, and use this as a reference to group them in combination with personal professional advantages. The purpose is to ensure that there are students with these four personality tendencies in each group as much as possible.

\subsection{Responsibilities of Students and Teachers}

After determining the team members, each team will divide their work and cooperate according to the animation production process, with the learning goal of completing high-quality animation short films. Give full play to everyone's creative advantages and contribute their own strength in script, art design, original animation design, post-synthesis and so on. In the creative process, share their creative experience, learn the excellent quality of team members, stimulate innovative and creative thinking through "brainstorming" activities among team members. Establish cooperative consciousness of interdependence and sharing weal and woe, experience the hardships of "joint entrepreneurship" and form a win-win situation of cooperation. The completed works directly enter the competition link and accept the social test.

In the whole process of cooperative learning, teachers play a guiding role rather than a dominant position. On the basis of unchanged general direction, they guide students, teachers and students to carry out interactive discussions, periodic special reporting activities. It can lead to transform innovative thinking into operable objects, communicate good creative points with other teams, and prompt each group to sort out the ideas of creative outline, etc. Before, during and after the creation, it will complete the phased questionnaire survey to understand the learning status of each student and the cooperation among team members, and give feedback and guidance in time according to the team situation.

For example, the short animation film Liangyi of Jimei University in 2021 was completed under the guidance of professional teachers and the cooperation of students to carry forward the theme of Chinese Tai Chi culture. At present, the film has won many awards, including the second prize of the digital animation group of the "15th China Good Creativity and National Digital Art Design Competition" in 2021, the second prize of the national level and the first prize of the provincial level in the 9th National Colleges and Universities Digital Art Design Competition, and so on. In addition, in the industry, the film also won the nomination of Chinese Young Animation Director Support Plan (Tencent Video x Wuhu) in 2021, and the excellent work award of "BiliBili" 2021 Small Universe Plan.

The cooperative learning mode of "learning by competition" in animation major aims to improve students' innovation and entrepreneurial ability, establish a stable cooperative team as the strategy, cultivate students' learning atmosphere of mutual help and enhance students' sense of team responsibility. This model requires both teachers and students to have innovative consciousness and the ability to push through the old and bring forth the new. It is also an important way to broaden the vision of teachers and students, integrate theory with practice, support innovation and entrepreneurship teaching.

\section{UNIVERSITY ENTERPRISE COOPERATION AND COLLABORATIVE EDUCATION STRATEGY}

\subsection{Advantages of University Enterprise Cooperation and Collaborative Education}

The innovation and entrepreneurial ability of students have certain limitations because of only being taught in colleges and universities. It is easy to produce students' innovative thinking and entrepreneurial objectives that do not meet the requirements of the industry. It results in confusion of teaching contents and objectives, low teaching efficiency and difficult to make a qualitative leap in teaching effectiveness.

Colleges and universities are the cradle of cultivating talents. The linkage between university and enterprise aims to training characteristic talent with the demand of enterprises, formulating talent training plans and jointly building cooperation platforms. It can not only enhance the training level of innovation and entrepreneurial ability, but 
also effectively solve the problem of talent supply. University enterprise cooperation and collaborative education can overlap the educational advantages of them. The enterprise has an innovative consciousness accord with product positioning and market demand, advanced science and technology to improve its creative ability, and excellent entrepreneurial experience for observation and learning.

\subsection{Construction of University Enterprise Joint Studio}

The deep integration of industry, study, research and education is to realize the deep combination of specialty and industry, and the deep integration of curriculum and enterprise practice in the talent training mode of colleges and universities, which plays a positive role in innovation, entrepreneurship and creation education and practice.[6] The university enterprise joint studio is the link between colleges and universities and enterprises. In this studio, professional teachers of the universities and project technicians of enterprises jointly form a tutor team. According to the respective advantages and characteristics of colleges and universities and enterprises, they jointly negotiate and formulate innovation and entrepreneurship teaching plans and outlines, such as innovation and entrepreneurship training courses, animation derivatives design, animation product marketing, graduation internship, professional investigation and other courses.

In the joint studio, some excellent students from four grades can be selected to form a cross grade project team, which is jointly guided by colleges and universities and enterprise tutors. The studio undertakes part of the project production of the enterprise and improves the teaching effect in the practice of real animation projects. In addition, as students are a cooperative team composed of cross grades, a learning mode of "old with new" can be formed in the team, so as to optimize the technical transmission level of the creative echelon and improve the effect of cooperative learning.

\subsection{Introduction of Enterprise Project into Classroom Teaching}

Select the appropriate part from the projects in progress or in the planning stage of the enterprise and introduce it into the teaching of professional basic courses as the content of teaching practice. And employ the technical personnel of the project team as the course teaching assistant. In the early stage of the course, explain the production background and completion of the project for students, and put forward corresponding expected objectives and achievement requirements. In the process of students' creation and practice, professional teachers are responsible for the teaching and Q \&amp; A of basic theoretical knowledge and technology. For the cutting-edge digital technology used in creation, enterprise teaching assistants teach teachers and students in the form of special lectures. This method can not only expose students to real industry projects, but also help teachers and students of colleges and universities solve the problem of lagging behind enterprises in cutting-edge digital technology. After the course, professional teachers and enterprise teaching assistants will jointly evaluate the results, and enterprise teaching assistants will host work evaluation activities in the class. It can be compared with enterprise creative results to find out the advantages and defects in students' works.

\section{CONCLUSION}

Animation products are creative cultural products, and the comprehensive expression of the creator's innovative spirit and creative ability. The ports at all levels from upstream to downstream of whole industrial chain, which are supported by the derivation and sales of animation products, are good ways to seek entrepreneurial breakthroughs. Animation education should be fully integrated with innovation and entrepreneurship education in a targeted way. According to the innovation and entrepreneurship knowledge framework system, it should jointly build a professional teaching model to improve innovation and entrepreneurship ability. Also, it should build a complete knowledge system around the whole chain of "curriculum-practice-competitionemployment". Through cultural knowledge and digital technology, it realizes the whole process of generation and sales of original products accord with industry standards shall be realized. As a result, the value-added effect of professional teaching shall be improved, and more excellent industry talents for the development of national culture and economy shall be cultivated.

\section{ACKNOWLEDGMENTS}

This work was supported by The Undergraduate University Education and Teaching Reform Project in Fujian Province (FBJG20200173), The Project of Industry and Science Cooperation and Cooperative Education from the Ministry of Education (202002064009), and The Ninth Key Education and Teaching Reform Projects of Jimei University (JY17010).

\section{REFERENCES}

[1] Lv Jing, Zhang Haidong. Vigorously Promoting Innovation and Entrepreneurship Education in Colleges and Universities (New Awareness) [DB/OL].(2020-04016)[2021-09-

2].http://paper.people.com.cn/rmrb/html/202004/16/nw. D110000renmrb_20200416_4-09.htm

[2] Wang Jue. Interdisciplinary Applied Animation Specialized Talent Training in the Context of New Liberal Arts Construction [J]. Educational Media Research 2020 (2): 60 
[3] Zhou Chengjun, He Zhangqiang, Yuan Shiqun. Design of Cultural and Creative Products [M]. Beijing: Chemical Industry Press, 2020: 43

[4] Chen Gelei. Principle of Super IP Incubation [M]. Beijing: China Machine Press, 2020:83
[5] https://baike.baidu.com/item/cooperative learning

[6] Xue Yong. Deep Integration of Industry and Education: System Generation of Talent Training Model in Colleges and Universities [J]. China Higher Education, 2020 (10): 58-60 